\title{
The Rowan Hillson Inpatient Safety Award 2018 for the best inpatient diabetes educational programme for healthcare professionals
}

\author{
UMESH DASHORA, ${ }^{1}$ MIKE SAMPSON, ${ }^{2}$ ERWIN CASTRO, ${ }^{1}$ DEBBIE STANISSTREET, ${ }^{3}$ CHRISTINE JONES, ${ }^{2}$ \\ ROWAN HILLSON ${ }^{4}$ ON BEHALF OF JOINT BRITISH DIABETES SOCIETIES FOR INPATIENT CARE
}

\begin{abstract}
Introduction: The annual National Diabetes Inpatient Audit (NaDIA) in the UK continues to show a high incidence of insulin errors in patients admitted to hospital with diabetes. It is clear that new initiatives are urgently required to mitigate this risk.

Method: The Joint British Diabetes Societies for Inpatient Care (JBDS-IP) organised the fifth national Rowan Hillson Inpatient Safety Award on the theme of the best inpatient diabetes educational initiative to improve patient safety in hospitals.

Result: The winner was Kath Higgins and the team from the University Hospitals of Leicester NHS Trust for their ITS Diabetes - Inpatient Diabetes Training \& Support programme an educational toolkit accessible to medical, nursing and pharmacy staff. Components included face-to-face training, e-learning module, monthly newsletter social media communications with competency document and flashcards. The initiative reduced insulin errors and in-hospital diabetic ketoacidosis. There were two teams in second position. Michael Lloyd and colleagues from St Helens and Knowsley Teaching Hospitals NHS Trust received the award for their individualised and shared insulin prescribing error feedback system, Safe Insulin TipS (SIPS), and multi-professional simulation-based training. Ruth Miller and colleagues in North West London were commended for the project to implement Diabetes 10 Point Training in Acute Hospitals across North West London. This clinically-based teaching programme
\end{abstract}

Diabetes and Endocrine Centre, Conquest Hospital, Hastings, UK

Elsie Bertram Diabetes Centre, Norfolk and Norwich University Hospitals NHS Foundation Trust, Norwich, UK

3 Diabetes Centre, Lister Hospital, East and North Hertfordshire NHS Trust, UK

Former National Clinical Director for Diabetes, Department of Health, UK

Address for correspondence: Dr Umesh Dashora

Consultant, Diabetes and Endocrinology, Conquest Hospital, The Ridge,

St Leonards on Sea TN7 7RD, UK

Tel: 01424755255

E-mail: u.dashora@nhs.net

https://doi.org/10.15277/bjd.2020.264
Results of Rowan Hillson Insulin Safety Award 2018

Winner:

Dr Kath Higgins and the team from the University Hospitals of Leicester NHS Trust for 'ITS Diabetes Inpatient Diabetes Training \& Support - implementing an educational strategy for frontline staff'

Joint Runners up:

Dr Michael Lloyd and colleagues from St Helens and Knowsley Teaching Hospitals NHS Trust 'Improving insulin prescribing and knowledge of the management of diabetes emergencies'

Ruth Miller and colleagues in North West London for 'The implementation of the Diabetes 10 Point Training in Acute Hospitals across North West London'

provided quick training specifically designed for all hospital settings to address the commonest diabetes errors.

Conclusion: These and similar schemes need to be developed, promoted and shared to reduce insulin errors in hospitalised patients with diabetes.

Br J Diabetes 2020;20:151-154

Key words: inpatients, safety, award, diabetes, educational, programme, healthcare, professionals

\section{Introduction}

Insulin and medication errors are common and preventable. Since the first National Diabetes Inpatient Audit (NaDIA), a number of attempts such as bespoke e-learning modules, 'ThinkGlucose' programmes, education of junior doctors regarding diabetes management during their induction and modifications in prescription charts have been developed to improve insulin safety. As a result, between 2010 and 2017 subsequent NaDIA results demonstrated some reduction in errors related to inappropriate insulin infusions ( $7.4 \%$ to $6.3 \%)$, medication errors $(44.5 \%$ to $31.3 \%)$, prescribing errors $(30.7 \%$ to $19.0 \%)$, glucose management errors (24.1\% to $18.5 \%)$, insulin errors ( $25.8 \%$ to $18.6 \%$ ), mild hypoglycaemia ( $22.8 \%$ to $16.7 \%$ ) and 
severe hypoglycaemia (11.8\% to $7.1 \%$ ) in hospitalised patients with diabetes in the UK. ${ }^{1} \mathrm{NaDIA}$ results also showed that there is considerable variation between Trusts and sometimes at different times within the same Trust. ${ }^{1}$ Clearly, further improvements are needed to improve patient safety in hospital inpatients with diabetes.

Following the success of previous contests to find the best insulin prescription chart, ${ }^{2}$ the best hypoglycaemia avoidance initiative, ${ }^{3}$ the best joint pharmacy and diabetes team initiative ${ }^{4}$ and the best digital initiative, ${ }^{5}$ JBDS-IP launched the fifth round of this national competition in 2018 to find the best educational innovation with positive impact on patient safety so that effective practices can be identified, rewarded and shared with the other Trusts in the UK.

Dr Rowan Hillson chaired the judging panel which consisted of Dr Clare Crowley, Medicines Safety Pharmacist, Oxford University Hospital NHS Trust; Emma Green, Paediatric Diabetes, Specialist Nurse, University Hospitals of Leicester NHS Trust; Sarah Gregory, Diabetes Inpatient Specialist Nurse, East Kent Hospitals University Foundation Trust and Dr Anne Kilvert, Consultant Diabetologist, Northampton General Hospital NHS Trust.

\section{Results}

\section{Winner}

Dr Kath Higgins (kath.higgins@uhl-tr.nhs.uk) and the team at the University Hospitals of Leicester NHS Trust won the award for their project called Inpatient Diabetes Training \& Support (ITS) initiative, an educational toolkit accessible to medical, nursing and pharmacy staff. Components included face-to-face training, e-learning module, monthly newsletter and social media communications with competency document and flashcards. An externally hosted web-based junior doctors' inpatient diabetes handbook accessible via all platforms (PC, iPad, smartphone and laptop) was used to spread the messages which were consistent across the resources and included all major areas of diabetes. The project had executive support. Evaluation was done using an abbreviated version of the NaDIA audit with data collected quarterly, Datix reports and in-hospital diabetic ketoacidosis (DKA) data. Insulin errors reduced by $50 \%$ (from $45.5 \%$ to $22.8 \%$ ), inhospital DKA reduced from one a month to zero, compliance with insulin safety training increased from $40 \%$ to $62 \%$ for medical staff and Datix reporting increased from 468 in 2016 to 626 in 2018 as awareness about the errors increased. The project had added strengths such as involvement of all healthcare professionals, utilisation of various learning methods including simulation and e-learning and engagement of a wide range of professionals to deliver education. Qualitative feedback was highly positive with comments like "I did the online module and I would like to say it's actually rather easy to follow and really good".

\section{Runners up}

The runners up were so close to each other that there were two this year:

Dr Michael Lloyd (Michael.Lloyd@sthk.nhs.uk) and colleagues at St Helens and Knowsley Teaching Hospitals NHS Trust were awarded for their individualised and shared insulin prescribing error feedback system led by the pharmacists, weekly delivery of 12 Safe Insulin TipS (SIPS) to nurses and doctors and multi-professional simulation-based training for the management of hypoglycemia and DKA. Pre- and post-questionnaire based evaluation was done to evaluate the impact of these learning events. There was a significant reduction in insulin errors following the intervention from 80 errors to 69 errors $(p<0.05)$. Qualitative feedback also showed a significant improvement with simulation-based training and SIPS, with comments like "Really enjoyed the session".

Ruth Miller (ruth.miller2@nhs.net) and colleagues in North West London were awarded for their concise and focused project to implement Diabetes 10 Point Training in Acute Hospitals across North West London covering eight CCGs catering for 148,000 people with diabetes. The programme covered areas like listening to people with diabetes, types of diabetes, foot care, hypoglycaemia, hyperglycaemia, insulin prescribing and administering, managing tube-fed people with diabetes, indications for intravenous insulin, DKA/hyperglycaemic hyperosmolar state and how to refer to the diabetes team. This clinically-based teaching programme within the clinical areas provided quick training specifically designed for all hospital settings to address the commonest diabetes errors. Pre- and post-training selfreported confidence scores improved in the 716 members of staff from Ealing, Hammersmith, Hillingdon, Imperial, St Mary's and Charing Cross Hospitals who attended the sessions. The programme used aide-mémoire cards in addition to paper and PowerPoint material, and people with diabetes were heavily involved in the evolution of the programme. Plan-Do-Study-Act improvement cycles were used with a pilot on a ward to ensure continuous refinement of the programme which was provided by scheduled sessions supported by ward drop-ins by specialist nurses. The sessions were 20 minutes long and focused on the needs of the clinical area (eg, intravenous insulin training for surgical wards for perioperative management).

The programme resulted in a significant reduction in insulin errors in the NaDIA audit cycle and improvement in self-reported confidence by hospital staff. Qualitative feedback was also positive with comments like "Completely mind blowing and has changed the way I think about diabetes". There is a plan to work on Digital 10 Point Training in 10 minutes which will spread the knowledge more widely. The training can be provided by anybody who has done a train-thetrainer course of half a day and super-trainers have been identified to spread the knowledge further.

\section{Ideas from other entries}

\section{East Sussex Healthcare NHS Trust: 'Safe use of insulin essential to role'}

Erwin Castro (ecastro@nhs.net) and the diabetes team at East Sussex Healthcare NHS Trust pioneered a number of novel educational approaches including a comprehensive 3-hour insulin education session with PowerPoint slides. Twelve sessions are delivered for acute staff and 12 for community staff every year. Assessment of clinical competencies in the administration of subcutaneous insulin was done using a structured form based on a journal article and signed by the assessor as novice, competent practitioner or expert practitioner. 
A total of 590 staff was able to attend safe use of insulin training. The number of incidents related to safety of insulin reduced in relation to administration of insulin ( $29 \%$ reduction from 24 to 17 ) and prescription of insulin (36\% reduction from 22 to 14) between 2017 and 2018 as per Datix data, whereas omission of insulin remained the same in this period (from 16 to 16). All 122 participants in the training course rated it excellent or good. Qualitative feedback was highly positive with comments like "The treatment of hypos and different types of insulin was the most useful aspect of the course for me".

The monthly educational sessions were supported by a yearly insulin safety week. This educational project involved and secured support from pharmacy, directors of nursing and midwifery, heads of nursing and midwifery, medical education, other allied healthcare professionals, other specialties, community nursing teams, local diabetes UK group, Listening into Action, Learning and Development and the communication department. The project of insulin safety week has spread to 250 other participating Trusts in the country.

\section{Kingston Ward Champion Programme}

Claire Neely (claireneely@nhs.net) and the Kingston hospital diabetes team submitted their project of developing a diabetes Ward Champion Programme. The champions were chosen through an application process asking them what they felt needed to change in their clinical area and supported by their managers. They went through six classroom-based modules over six months followed by the second part of the programme over the next six months when supporting the patients on the ward and finally leading to a follow-up day a year later to present their work and achievement and receive some white belt training endorsed by NHS innovation and improvement in problem solving techniques. The effectiveness of teaching was measured by a pre- and post-session knowledge questionnaire. Hypo box audit, NaDIA staff knowledge audit and patient satisfaction audit following the intervention showed steady improvement from 2016 to 2018. There were some excellent examples of projects undertaken by the ward champions like poster on ward focus board illustrating healthy eating, insulin regimens, hypoglycaemia treatment and foot assessments; information campaign including teaching, mini flip chart attached to medicine trolley with information re hypoglycaemia and when to administer insulin and ward folder contacting local policies and charts; bed head board with a coloured sign to indicate that the patient has diabetes, handover sheet prompts to give insulin first and targeted teaching; lectures in AAU/A\&E and hypo boxes on crash trolleys; informing the patients to bring their medications when coming for day surgery as they may have to stay overnight in some cases; foot assessment reminders on PC; and random fact reminders on a poster including podiatry contact numbers.

\section{West Suffolk hypoglycaemia simulation training}

Carry Beecroft (caroline.beecroft@wsh.nhs.uk) and team developed a hypoglycaemia simulation training immediately following 30 minute classroom-based teaching within an acute hospital setting.

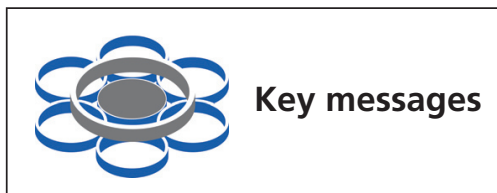

- The Rowan Hillson Inpatient Safety Award is a project developed to identify and promote best hospital innovations in the UK to improve safety of patients

- The 2018 award was to identify the best inpatient diabetes educational initiative to improve patient safety in hospitals.

- The winner was Dr Kath Higgins and the team from the University Hospitals of Leicester NHS Trust for their ITS Diabetes (Inpatient Diabetes Training \& Support) educational toolkit accessible to medical, nursing and pharmacy staff. Components included face-to-face training, e-learning module, monthly newsletter and social media communications with competency document, simulations and flashcards. The initiative reduced insulin errors and in-hospital diabetic ketoacidosis.

- There were two teams in second position. Dr Michael Lloyd and colleagues from St Helens and Knowsley Teaching Hospitals NHS Trust received the award for their individualised and shared insulin prescribing error feedback system, Safe Insulin TipS (SIPS), and multiprofessional simulation-based training. Ruth Miller and colleagues in North West London were recognised for their project to implement Diabetes 10 Point Training in Acute Hospitals across North West London.

This method of teaching improved the confidence of $93 \%$ of the team in managing hypoglycaemia in pre- and post-simulation questionnaires. Qualitative feedback was quite positive with comments like "The simulation training actually puts you in a real-life situation. You have to deal with the situation; this is how I learn best".

\section{Prince Philip Hospital diabetes real-time staff training}

Dr Sam Rice (Sam.Rice@wales.nhs.uk) and colleagues developed a simple inpatient hypoglycaemia prevention education tool that led to a reduction in severe hypoglycaemia from $15 \%$ to $3 \%$ in the NaDIA audit in 2017. When the severe hypoglycaemia increased again to $9.5 \%$, the team developed an animation film of 5 minutes available via links or codes leading to a reduction in severe hypoglycaemia again. The initiative is available on the Diabetes UK shared resources now. The strength of the educational tool is its brevity and accessibility at any time of the day by the hospital staff, not only to understand and treat hypoglycaemia but also to learn how to prevent it in the future. The feedback was hugely positive with comments like "This is great because I can just pull it on my phone as and when I need it".

\section{Summary and conclusions}

The competition revealed some excellent examples of educa- 
tional initiatives which have resulted in tangible benefits for staff and patients. The Leicester team won the award as they were able to reduce insulin errors and in-hospital DKA with their multipronged strategy using face-to-face training, e-learning, monthly newsletter, social media communications, competency assessments and flash cards. The St Helens and Knowsley team secured the joint runner-up position as they were able to reduce insulin errors by a combination of an individualised and a shared insulin prescribing error feedback system run by a pharmacist supported by regular tips to promote insulin safety and simulation training. The North West London team was the other joint runner-up for their 10-point education and training project which provided quick and relevant training to the staff in their respective departments. We all need to promote and share these ideas and develop new ones to help increase patient safety in our hospitals for people with diabetes.

Acknowledgements: The Rowan Hillson Inpatient Safety Award is run by Joint British Diabetes Societies for In-patient Care (JBDS-IP) group with financial support from the Association of British Clinical Diabetologists $(A B C D)$ and Diabetes UK.
Conflict of interest: UD reports personal fees from AstraZeneca, Sanofi, Novo Nordisk, Lilly, Bl, outside the submitted work. RH was National Clinical Director for Diabetes, Department of Health. All other authors have nothing to declare.

Funding: None

\section{References}

1. NHS Digital. National Diabetes Inpatient Audit 2017. https://digital.nhs.uk/data-and-information/publications/statistical/national-diabetes-inpatient-audit/national-diabetes-inpatient-audit-nadia2017 (accessed 29 April 2018)

2. Dashora U, Sampson MJ, Castro E, et al. Rowan Hillson Insulin Safety Award 'best in class' insulin prescription chart competition. Br J Diabetes 2015;15:135-8. http://dx.doi.org/10.15277/bjdvd.2015.028

3. Dashora U, Sampson MJ, Castro E, et al. The best hypoglycaemia avoidance initiative in the UK. Br J Diabetes 2017;17:74-7. https://doi.org/ 10.15277/bjd.2018.195

4. Dashora U, Sampson M, Castro E, et al. The best joint pharmacy and diabetes team initiative to improve insulin and prescribing safety in hospital. Br J Diabetes 2018;18:163-6. https://doi.org/10.15277/bjd.2018.195

5. Dashora U, Sampson M, Castro E, et al. The Rowan Hillson Inpatient Diabetes Safety Award 2017 for the best digital initiative. Br J Diabetes 2018;18:110-12. https://doi.org/10.15277/bjd.2018.182

\section{MiniMed ${ }^{\mathrm{TM}}$ 780G System}

Automated to help more patients reach gylcaemic targets with less effort

For more information visit out website www.medtronic-diabetes.co.uk 